\title{
A TRAJETÓRIA DO PADRE PARDO DANIEL PEDRO MARQUES DE OLIVEIRA: A ESCRAVIDÃO NOS PERIÓDICOS DA PROVÍNCIA DO AMAZONAS (1860-1870)
}

\author{
THE TRAJECTORY OF THE BROWN PRIEST DANIEL MARQUES DE \\ OLIVEIRA: THE SLAVERY IN THE PERIODICAL OF THE \\ AMAZONAS PROVINCE (1860-1870)
}

DOI: http//dx.doi.org/10.15448/2178-3748.2017.1.22890

Tenner Inauhiny Abreu

Professor Assistente na Universidade do Estado do Amazonas tabreu@uea.edu.br

\begin{abstract}
RESUMO: O presente artigo intitulado A trajetória do padre pardo Daniel Pedro Marques de Oliveira: a escravidão nos periódicos da província do Amazonas (1860-1870) tem como enfoque central a trajetória política de um ex-escravo padre Daniel, tipificado como pardo livre que foi entre as décadas de 1860-1870 personagem de significativa relevância no cenário político da sociedade amazonense do oitocentos. Utilizamos como aporte teórico as discussões em torno do uso de periódicos enquanto fonte polissêmica, ressaltando o caráter complexo que tais fontes podem apresentar. $\mathrm{O}$ artigo encontra-se dividido em duas partes: a primeira de maneira sumária tratando do nascimento do periodismo do Amazonas a segunda parte analisa a trajetória política do padre pardo (liberto) Daniel Pedro Marques de Oliveira a partir de fontes oficiais de jornais da Província do Amazonas.
\end{abstract}

PALAVRAS-CHAVE: História, Periodismo, História do Amazonas , Escravidão

ABSTRACT: The present article entitled as "The Trajectory of The brown priest Daniel Marques de Oliveira: The Slavery in The periodical of The Amazonas province (1860-1870)" has as a central approach the policy trajectory of an ex-slave, The priest Daniel, represented as a free 'pardo' than was, between The decades of 18601870, a significantly carachter in the politics scenario of The society from Amazon in The XIX century. As a theorist support, we use The discussions around using periodical as a polissemic source, approaching The complex feature that those sources May show up. This article is asunder in Two pieces: The first one in a summary way, operating The periodical borning of Amazon and, after, we analyze The policy trajectory of the priest brown Daniel Pedro Marques de Oliveira using officer sources of magazines of The Amazon Province.

KEYWORDS: History; Journalism; History of Amazonas; Slavery.

A história do Amazonas, em relação aos estudos sobre escravidão vêm sofrendo uma considerável ampliação em seus estudos: dissertações, teses ou mesmo resultados de pesquisas tentam vencer a lógica reducionista e economicista (os escravos eram poucos e quase sem impacto na base econômica) cristalizada na historiografia regional tradicional.

Estes novos trabalhos ao se debruçarem sobre um tema clássico: a escravidão, apontam para o uso de novos aportes teórico-metodológicos e a diversificação de fontes para 
o estudo da temática da escravidão no Amazonas. Em se tratando do período provincial e dos estudos sobre as populações escravizadas os jornais são documentos complexos por apresentarem diversos atores sociais e sua atuação na dinâmica de uma sociedade onde a escravidão não é a base da economia, mas enquanto instituição organiza esta sociedade e cristaliza hierarquias sociais.

Durante as décadas de 1860-1870 populações escravizadas, estavam, portanto, dispersas por toda província do Amazonas e como podemos observar suas ações e estratégias de resistência e busca de ascensão social estavam presentes nas páginas dos jornais, compreendidos neste artigo como produtos sociais que apresentam as ideias de grupos sociais distintos não apenas das elites provinciais.

Entre estes indivíduos, que aparecem nas páginas dos jornais e que são tipificados como oriundos do cativeiro uma figura se destaca no cenário das disputas entre facções da elite política e as populações escravizadas no Amazonas do oitocentos: trata-se do padre pardo Daniel Pedro Marques de Oliveira que busca se afastar da experiência do cativeiro e ampliar suas relações políticas na então província do Amazonas das décadas de 1860 a 1870.

Este artigo objetiva, portanto, analisar a partir dos jornais, a trajetória deste liberto que utilizou de estratégias para atuar e se destacou no cenário político chegando a ocupar o cargo de deputado provincial no Amazonas durante estas décadas para tanto fez necessário um esboço teórico-metodológico a respeito dos jornais enquanto fonte histórica.

$\mathrm{O}$ texto encontra-se divido em duas partes na primeira intitulada os periódicos na província do Amazonas descreve-se o referencial teórico bem como as possibilidades do uso do jornal enquanto fonte na mesma seção aborda-se sumariamente o início do periodismo no Amazonas do oitocentos.

Na segunda parte intitulada o caso do padre pardo Daniel Pedro Marques de Oliveiro busca-se demonstrar um protagonismo da atuação do padre pardo Daniel Pedro a partir da descrição e das análises de trechos extraídos dos jornais o que aparecem as ações e falas do padre.

\section{Os periódicos na província do Amazonas}

O surgimento da imprensa na Província do Amazonas, conforme destaca Maria Luiza Pinheiro (2001) teve caráter tardio e com lento desenvolvimento. Heloísa Cruz (2007) classifica a imprensa como um manancial fértil para o conhecimento do passado, fontes ricas para a recuperação dos acontecimentos históricos. Entretanto a autora afirma que: 
Pensar a imprensa como esta perspectiva implica, em primeiro lugar, tomá-la como uma força ativa da história do capitalismo e não como mero depositário de acontecimentos nos diversos processos e conjunturas. (...) é preciso pensar sua inserção histórica enquanto força ativa da vida moderna, muito mais ingrediente do processo do que registro dos acontecimentos, atuando na constituição de nossos modos de vida, perspectiva e consciência histórica (2007, p. 257).

Os diversos materiais da Imprensa, dentre eles os jornais, segundo Heloísa Cruz (2007), não existem para que os historiadores e cientistas sociais façam pesquisa. Transformar um jornal ou revista em fonte histórica é uma operação de escolha e seleção feita pelo historiador e que supõe seu tratamento teórico e metodológico. Trata-se, na visão de Cruz, de:

entender a Imprensa como linguagem constitutiva do social, que detém uma historicidade e peculiaridades próprias, e requer ser trabalhada e compreendida como tal, desvendando, a cada momento, as relações imprensa/sociedade, e os movimentos de constituição e instituição do social que esta relação propõe (2007, p. 258).

Na visão de Lilia Schwarcz (2008) os jornais são concebidos como produtos sociais, portanto, socialmente reconhecidos e como objeto de expectativas e representações específicas. A seleção do jornal enquanto documento básico é significativa como fonte histórica, de acordo com a autora, na medida em que o documento é bastante complexo já que no jornal observa-se a convergência de opiniões e posicionamentos políticos diversos.

José Bezerra Neto (2000) identifica o jornal como um espaço de disputa social, onde estão presentes discursos de determinados grupos a respeito de outros. Em sua obra Fugindo, sempre fugindo, afirma, o seguinte pensamento de Gilberto Freyre, que os jornais (no caso específico os anúncios de fuga de escravos) tratam do ethos da sociedade local por onde se pode compreender as contradições da própria sociedade sob o qual os jornais elaboram discursos. (Bezerra Neto, 2000, p. 01)

Os jornais como fonte de investigação historiográfica, segundo Maria Luíza Pinheiro (2001), para o Amazonas, contam apenas com a elaboração de catálogos e listagens auxiliares de pesquisas) que não trazem grande profundidade interpretativa das publicações. As obras locais que tratam da história do Amazonas usando como fonte os jornais no geral, de acordo com a autora se constituem meramente de listas contendo a descrição de títulos e características físicas dos periódicos, tais como proprietários, edições, tamanho físicos dos exemplares etc. A imprensa, para Santos:

Apesar de ser incipiente, a imprensa no século XIX era o único veículo eficiente de comunicação de massa, cumprindo nesse período um importante 
papel. Essa imprensa do século XIX, num primeiro momento, é uma "imprensa áulica", que se limita sobretudo a publicações de atos governamentais das Províncias e do Império (1990, p. 19).

Em sua obra, Folhas do Norte, Pinheiro (2001) aborda o processo de formação do periodismo no Amazonas, analisando as características gerais, bem como suas linhas centrais e sua articulação em um contexto social marcado por forte tradição de oralidade. Segundo a autora a sociedade amazonense do oitocentos e constituída por uma minoria de pessoas alfabetizadas, convivendo ainda com as línguas indígenas e a língua geral, que disputam espaços no Amazonas com a língua portuguesa. Tal fato reforça a característica de uma sociedade onde a circulação de informações passa principalmente, mas não unicamente, pela comunicação oral. E neste cenário que surge, para a autora, o periodismo no Amazonas.

Ao buscar dar visibilidade a determinada categoria de trabalhadores e tentando recuperar suas experiências sociais, Pinheiro (2001) constata que as chamadas fontes de caráter oficial (relatórios, exposições, mensagens de governo) reforçavam uma postura historiográfica de silêncio diante dos segmentos sociais, notadamente os trabalhadores que circulavam pela cidade de Manaus. Nesse cenário a autora aponta a necessidade de se pensar o periodismo no Amazonas, “(...) buscando uma compreensão tanto do papel por ele desempenhado, quanto dos dilemas no momento de sua introdução no contexto regional.” (2001, p. 11).

J. B. de Farias e Souza ao constatar a "emergência do periodismo no Amazonas", de acordo com os dados tabulados a partir da obra A Imprensa no Amazonas, faz o levantamento dos periódicos no século XIX no Amazonas:

(...) os trinta anos que se seguiram ao surgimento do primeiro jornal da província (o Cinco de Setembro, de 1851) podem ser caracterizados como o momento embrionário da imprensa, com a veiculação de um número bastante modesto de títulos (são apenas 46, ou 12,4\% do total de 371 dos jornais arrolados por J. B. Faria e Souza; uma qualidade gráfica precária, visível na presença relativamente maior de folhas manuscritas e/impressas e pequenos formatos; uma exiguidade de jornais diários além da efemeridade da grande maioria dos títulos (PINHEIRO, 2001, p. 62).

Entre 1851 e 1880, este primeiro grande momento do periodismo no Amazonas é caracterizado por Maria Pinheiro (2001) como de lenta expansão. Utilizando-se das palavras de Marvignier de Castro, a autora descreve este período em relação aos principais jornais afirmando que: 
Depois do 'Estrela do Amazonas', ex ' 5 de Setembro', editado por Manuel da Silva Ramos, inúmeros periódicos foram saindo à luz da publicidade. Raro era o ano em que não surgisse novo órgão defensivo dos interesses do Povo. 'Vigilante' foi o segundo semanário aparecido na capital em 1859 , 'O Catequista' em 1860, 'O Progressista', em 1862. Afora alguns folhetos mensais ou bi-anuais, até 1866 foi 'O Amazonas' o maior diário que se publicara em Manaus” (CASTRO, apud PINHEIRO p. 62).

Quase todos os jornais utilizados por Maria Luiza Pinheiro (2001) demonstravam estar comprometidos com os mecanismos vigentes de controle e dominação, apesar de que “(...) muitos traziam colunas, e sessões que, espremidas entre suas páginas secundárias, davam a ver os populares e os temas mais corriqueiros do viver urbano.” (p. 11). Tais colunas, conforme destaca a autora, traziam uma carga preconceituosa e muitas vezes pejorativa para com as camadas populares da sociedade local. Neste aspecto podemos afirmar, que os jornais revelam-se importantes fontes de informação por onde é possível perceber múltiplas dimensões do viver social.

O discurso presente nos jornais assume interesses de grupos e facções, o que permite a percepção das tensões e conflitos que permeiam a sociedade. Compreende-se, portanto, como podemos observar, a imprensa como prática social e momento de constituição/instituição dos modos de viver e pensar.

A investigação do periodismo como prática e ação cultural, pressupõe o rompimento com concepções restritivas. O periodismo seria, nas palavras de Maria Luiza Pinheiro (2001), indissociável do contexto social, de que faz parte. O entendimento, portanto do tema passa pela recuperação do conceito de cultura dentro da perspectiva da história social. Ressalta-se o caráter polissêmico do conceito de cultura, o que sob nosso entendimento faz com que seja necessário uma percepção da historicidade do termo.

De acordo com Pinheiro (2001) o termo cultura era comumente utilizado como uma “(...) projeção invertida da base socioeconômica. Não só separada da 'vida material', mas também sua mera derivação (...)” (p. 14).

Déa Fenelon (1993) ressalta que a cultura dentro dessa perspectiva era entendida como uma produção das coisas do espírito e das ideias, distanciando-se da correlação da sociedade. Afirma que a base de discussão sobre a teoria da cultura vem da disposição de aceitá-la como processo social que modela modos de vida globais e não apenas considera-la como uma teoria das artes e vida intelectual em relação com a sociedade.

Raymond Williams em sua obra Cultura (1992) ao se referi ao termo "cultura" afirma a dificuldade de definição do termo que começa como um processo culminando na ideia de 
um "modo de vida global". O termo cultura, ainda de acordo com o autor utilizado de maneira ampla e pluralista designava um modo de vida global e característico, sendo empregado com uma gama de significados desde pessoa de cultura; atividades culturais; artes e trabalho intelectual.

\section{O caso do padre Pardo Daniel Pedro Marques de Oliveiro}

O padre Daniel Pedro Marques de Oliveira denunciou ao Presidente da Província em janeiro de 1874, conforme citação abaixo extraída do livro de ofícios da Câmara Municipal de Vila Bela, que a mulata Benedita, estava sendo mantida irregularmente como cativa na Vila de Silves por João Roiz Terço. Benedita é descrita pelo padre como "mulata" e "infeliz brasileira”, portanto aos olhos do sacerdote, o mesmo estava defendendo os direitos de uma cidadã. $\mathrm{O}$ texto faz alusão à carta de alforria da mulata, conforme veremos a seguir.

Padre Daniel denuncia junto às autoridades a condição em que se encontrava a mulata Benedita, segundo o clérigo, liberta em agosto de 1873. Descreve a situação irregular perante a lei, como zombaria, e afirma que a mulata sofria tratamento bárbaro pelo seu algoz, caracterizado como homem violento e de péssimos precedentes:

(...) Pela inclusa carta de alforria, verá V.Exa. quea mulata Benedita é liberta desde 30 de Agosto de 1873. Sendo, porém, público e notório nesta vila, que essa infeliz continua a viver até esta data debaixo de um cruel cativeiro, sofrendo que diariamente (?) os mais bárbaros tratamentos de João Roiz Terço ${ }^{1}$, homem de gênio violento e de péssimos precedentes; que, por vezes, tem aqui zombado da lei e da autoridade, recorro à $\mathrm{V}$. Exa.,rogando-lhe se sirva garantir a liberdade dessa infeliz brasileira. Levando este fato ao conhecimento de V. Exa., creio que cumpro um dever inerente ao meu ministério, qual o de proteger os infelizes e desvalidos, máxime os que estão confiados à minha jurisdição espiritual. (...) (ARQUIVO PÚBLICO DO ESTADO DO AMAZONAS - Livro de Ofícios remetidos pela Câmara Municipal de Vila Bela, 1873).

Como podemos observar no texto acima, padre Daniel ao denunciar as sevícias cometidas contra a liberta Benedita estava apenas "cumprindo um dever inerente ao seu ministério"; "proteger os desvalidos e os infelizes." Este era o papel do clérigo? Ou sua “jurisdição espiritual” se confundia com sua atuação política?

Não seria a primeira nem a última vez que padre Daniel estaria envolvido em questões polêmicas. Pardo Livre, acusado de diversos crimes, teve forte presença no cenário político da Vila de Silves, sendo virulentamente perseguido pelos seus adversários políticos,

${ }^{1}$ Conforme o original. Palavras em negrito são grifos nossos. 
(em via de regra autoridades locais, denunciadas por arbitrariedades) por conta de sua condição (liberto) e sua cor (pardo).

Em 1870 padre Daniel terminou a eleição provincial empatado em número de votos com Thomaz Luiz Simpson (31 no total) e quase assume o posto de deputado após a anulação da eleição de José Bernardo Michilles. Só não assumiu, pois o substituto de Michilles foi escolhido por sorteio. Em março de 1872 após mais de uma década de acirradas lutas, o sacerdote chega ao então posto de deputado da assembleia provincial. Isso sem falarmos da eleição anulada por sua participação da mesa eleitoral em 1863. Estamos, portanto diante de uma personagem que durante quase uma década esteve no centro das disputas políticas do período provincial no Amazonas e carrega consigo o peso da condição de liberto, além das marcas de sua origem: pardo. (ANAIS DA ASSEMBLEIA LEGISLATIVA DO AMAZONAS DE 1870-1871. Manáos: Impresso na Typographia Industrial, p. 02-04, 1882)

Em fevereiro de 1859 o Jornal Estrella do Amazonas noticia a prisão do sacerdote por agressão a uma autoridade:

No dia 15 - De ordem do sr. Dr. Chefe de policia o vigário da Villa de Silves, Daniel Pedro Marques de Oliveira e o alferes da guarda nacional Fidelles Alves da Costa, pronunciados pelo espancamento do ex subdelegado da mesma Villa Olimpio da Costa dos Santos por perjúrio (ESTRELLA DO AMAZONAS 9 de fevereiro de 1859).

Tal fato foi utilizado inclusive para o impedimento da participação de padre Daniel nas eleições provinciais. Foi solicitado o voto em separado do sacerdote, por conta do processo em que estava envolvido motivado pela suposta agressão ao sub-delegado de Silves. A mesa eleitoral recebera um requerimento solicitando o voto em separado do padre sob alegação de que padre Daniel estava sendo processado, o que suspenderia seus direitos políticos. De acordo com o a legislação da época, notadamente a constituição de 1824 o padre não poderia, por ser liberto ser votado ou presidir a mesa de votação, fato que gerou a anulação da eleição acorrida. Apesar disso o padre participa do pleito o que gerou criticas dos seus adversários que utilizaram os jornais para denunciar os fatos ocorridos:

A QUINZENA. - Manáos 9 de Janeiro (...) Domingo procedeo-se a eleição dos 8 membros e 4 suplentes d'Assemblea Legislativa Provincial, que devo dar o circulo d'esta Capital, sahindo eleitos os Deputados os Snres. Custodio Pires Garcia, Manoel Rodrigues Checks Nina, Vicente Alves da Silva, Dr. Jose Antonio de Freitas Junior, Padre Daniel Pedro Marques d'Oliveira, Joaquim Firmino Xavier, José de Carvalho Serzedello, e Francisco Antonio Monteiro Tapajos, que obtiverão maioria de votos na respectiva eleição; e Supplentes os Snres. Padre Manoel Lucupertino Salgado, Francisco de Paula 
Bello, e Manoel da Silva Ramos. A eleição ocorreo calma e sem a menor intervenção da autoridade, dando-se apenas uma pequena irregularidade de Um dos Eleitores requereo em termos que o voto do Eleitor Padre Daniel fosse tomado em separado, visto como está elle sujeito aos efeitos de uma pronuncia em cauza crime, e por tanto suspenso dos direitos políticos. Este requerimento porem, que tinha por fim arredar da eleição toda e qualquer ilegalidade e no qual devia votar todo o Collegio Eleitoral, foi peremptoriamente decidido pela Meza, que o dito Eleitor votasse englobadamente com os outros (ESTRELLA DO AMAZONAS 11 de janeiro de 1860).

De acordo com Pozza Neto (2011, p. 80)², entre as décadas de 1850 e 1870 cresce o movimento emancipacionista tanto no Brasil quanto na Província do Amazonas. O padre Daniel parece ter papel de destaque no cenário político da Província por se articular contra os interesses escravocratas inclusive sendo acusado de acoitar escravos em fuga.

Em 21 de março de 1860 o jornal Estrella do Amazonas noticia fato curioso a respeito do acoitamento de 8 escravos na Vila de Silves o padre Daniel Pedro foi um dos denunciantes do caso, demostrando como as autoridades burlavam a legislação vigente sobre o uso irregular da mão de obra escrava dos fugidos . De acordo com a notícia autoridades da Vila estavam envolvidos no caso:

Denunciados como escravos 8 individuos, que na villa de Silves acoutados escarnecião da lei e zombavão de direito de propriedade servião até cargos públicos; um de porteiro da Câmara Municipal e outro de cabo de trabalhadores (ESTRELLA DO AMAZONAS 21 de março de 1860.)

Interessante é que os escravos acoitados serviam como funcionários públicos na localidade, evidentemente com a "vista grossa" de autoridades locais:

O subdelegado e o commandante de trabalhadores, e o presidente da câmara são indigitados como protectores desses escravos, em consequência do que forão imediatamente demitidos os primeiros, a bem do serviço publico, e consta que o dr Chefe de Policia do Pará para averiguar o facto do acoutamento. (JORNAL ESTRELLA DO AMAZONAS 21 de março de 1860).

Foram de acordo com o noticiado no jornal capturados na Vila de Silves sete dos oito escravos fugidos, dentre eles uma escrava parda de nome Ignez com seus cinco filhos além, do cabo de trabalhadores que conseguiu evadir-se. Eram em conformidade com a nota, escravos de um proprietário paraense de nome Amanajás e o acoitamento gerou a destituição das autoridades envolvidas no fato.

\footnotetext{
${ }^{2}$ Dos dados coletados a respeito das alforrias na Província do Amazonas o autor afirma que o número de concessão de alforrias se concentra particularmente na década de 1870.
} 
O padre Daniel a partir dessa denuncia começa a se destacar como figura política que utiliza da denúncia como estratégia possível de combate aos abusos ou irregularidades cometidas pelos senhores de escravos no Amazonas.

Nascido em 28 de março de 1828, na cidade do Pará (Belém), filho de Anna Joaquina, mulata, escrava de seu pai José da Costa Albernaz, (o padre é, portanto pardo) teria sido liberto na pia batismal, de acordo com suas alegações expostas nos jornais supracitados.

Conforme texto do jornal $O$ Catechista, que desconstrói a argumentação do padre, de que ele seria livre, (o texto responde a artigo presente no jornal Estrella do Amazonas, daí conseguirmos ter acesso à fala do padre, e, portanto, as suas justificativas a respeito de sua condição):

O novo testamento, diz-nos o Rvm, proclama todos os homens livres, "logo sou livre"!. He verdade quanto ao que diz o Evangelho; mas esta verdade, e a consequência que tira estão em flagrante contradição com os factos no brasil nem todos são livres e prova está para si, mais que patente pois que nos confessa no seu granzel que sua mãe era escrava de José da Costa Albernaz, nos seguintes arrancos d'uma confissão pungente: meopresadissimopae único que, na terra PODE chamar-se senhor de minha idolatrada mãe ...

Logo a citação nada vem ao caso e me nos a consequência; pois que apesar do Novo Testamento, proclamar todos os homens livres, a mãe do Rvm, Sr. Daniel era escrava (O CATECHISTA, 12 de janeiro de 1863).

Talvez por esta razão tenha despertado tanto o ódio por parte de seus adversários que tentaram desqualificar seus discursos e dimensionar de maneira negativa suas ações políticas. As querelas presentes nas páginas dos jornais ultrapassam as disputas entre interesses políticos diferenciados, ganham conotação de ódio racial e preconceito contra a condição e a cor do Padre Daniel. O uso dos jornais como forma de externar posicionamentos políticos de distintos grupos nos propicia acompanhar de maneira indireta ao menos, as querelas entre o padre e as autoridades locais de Silves. Observa-se a partir dos jornais a atuação do padre Daniel no combate aos abusos das autoridades e dos senhores de escravos contra as populações escravizadas, o que somada a sua atuação enquanto padre e posteriormente deputado provincial o coloca no centro das disputas contra a escravidão na sociedade amazonense do oitocentos. O relato presente nos jornais, a denuncia do acoitamento dos escravos torna-se relevante pois explicita uma serie de questões que envolvem o mundo da escravidão no Amazonas provincial. A escravidão enquanto instituição organizando a 
sociedade e a dividindo hierarquicamente além das estratégias utilizadas pelas populações escravizadas para se afastar das experiências do cativeiro.

Ao buscar atacar politicamente o Padre Daniel, as autoridades veiculavam pelos jornais, acusações e impropérios que deixam transparecer de que maneira a sociedade da época via os libertos, os não brancos, ou seja, as experiências do cativeiro marcavam profundamente uma sociedade rigidamente estratificada e hierarquizada onde a cor se configurava em um dos aspectos discriminatórios a estes grupos.

Em 1863 o padre Daniel Marques de Oliveira estaria no centro das disputas políticas da província do Amazonas. As eleições foram anuladas por conta da mesa eleitoral ter sido presidida pelo sacerdote, fato proibido pelas leis imperiais que restringia os direitos dos libertos (o caso do padre Daniel) apenas a exercer o voto e não de serem candidatos. Sendo ele um ex-escravo não poderia, portanto exercer o comando da mesa eleitoral, muito menos ser candidato.

O jornal O Catechista publicou o assento de batismo do padre em busca de comprovar a condição do mesmo de liberto ou possivelmente escravo para ressaltar sua condição de egresso do cativeiro. $O$ Catechistaera periódico divulgador das atividades administrativas do Governo provincial no Amazonas. Pretendia-se, entretanto um jornal mais crítico, independente e imparcial no que diz respeito aos problemas da Província. Era um caderno semanal, tendo como sub-título "Folha Comercial", contendo quatro páginas divididas em três colunas. O primeiro número é de março de 1871. Este periódico exerceu grande influência política na época de sua edição, conforme assinala Santos (1990). O objetivo era restringir os direitos de participação política do padre Daniel, por conta de sua origem:

(...) [Certidão] - Certifico que revendo o Livro decimo septimo de assentos de baptismo da freguesia da Sé nelle a folhas uma até verso se acha o assento seguinte - Aos dez dias de Maio de 1830 annos, nesta cidade do Pará em a câmara Eclesiastica me foi apresentada uma peticao de José da Costa Albernaz, em seu seguimento uma certidão do Theor seguinte. - No dia vinte e oito de março de mil oitocentos e vinte oito nesta capella de Nossa Senhora da Estrella da fazenda de Pernambuco, baptiseisolememente e puz os Santos Oleos ao inocente Daniel filho natural de Anna Joaquina, mulata ESCRAVA de José da Costa Albernaz, (...) (O CATECHISTA, 5 de dezembro de 1863).

O articulista do jornal Catechista defende seu ponto de vista a respeito das alegações de que o padre era liberto ou mesmo escravo afirmando que: "Difficil é a situação do jornalista imparcial, quando forçado pelo dever discute um actopublico, e vê-se depois de 
frente para sustentar suas opiniões com uma questão pessoal, e odiosa. Tal é nossa actualsituação.” (O CATECHISTA, 12 de dezembro de 1863)

A visão de imparcialidade tinha duplo objetivo: primeiro convencer o leitor da veracidade dos fatos narrados, segundo esconder a vinculação de interesses expostos nas colunas dos jornais da época. Sidney Chalhoub (1986) em Trabalho, Lar e Botequim faz inclusive alusão à forma como as notícias eram produzidas no período. Referindo-se a Lima Barreto, afirma que em alguns casos era absolutamente corriqueiro entre os articulistas o uso da criatividade e a invenção dos fatos (maior floreio) principalmente nas chamadas das notícias.

No caso do Jornal Catechista, o articulista reitera sua posição em alegar que o padre Daniel oscilava entre a condição de liberto e escravo:

Sua Rvma. Porem, pela Estrella no. 795 de 2 do corrente, accusa-nos de libellista, o porque isto dicemos e tentando distruir nossa asseveração de seoestado liberto, cego apaixonado e mostrado sua ignorância, confessa se sintia escravo! (O CATECHISTA, 12 de dezembro de 1863).

A ideia da imparcialidade do jornalista, e, portanto a neutralidade da matéria publicada em si, defendia o ponto de vista do próprio jornal, na tentativa de convencer o leitor de que as eleições da Província do Amazonas aquele ano de 1863 deveriam ser anuladas, devido à condição do Padre Daniel e logicamente por conta de sua cor (ex-escravo, pardo):

Em o no. 83, discutindo as nulidades insanáveis das eleições porque passamos à pouco, fomos levados a mostrar entre outras causas, o ter sido o collegio da capital presidido por um liberto. Esse liberto, que apontamos então é o sr. Padre Daniel Pedro Marques de Oliveira (O CATECHISTA, 12 de dezembro de 1863).

Padre Daniel ao tentar se defender das acusações que sofria (a tentativa de impedimento da sua participação nas eleições provinciais) usa também os jornais para responder as acusações de ser ainda escravo ou liberto. Citando trechos das ordenações Filipinas e citações do Novo Testamento alega ser cidadão livre:

A ordenação [Liv. 4 Tit. 92 pr. e Reper] nosso direito pátrio civil proclama que o filho que o homem solteiro peão houver de alguma escrava sua he livre e lhe sucede na herança: eu succedi na herança de José da Costa Albernaz, senhor de minha mãe logo sou livre (O CATECHISTA, 12 de dezembro de 1863).

Vejamos a partir da resposta do jornal $O$ Catechista a fala do sacerdote: 
O Rvm. escravose não provar com documento que foi alforriado, ou não nos mostrar que o tribunal para o qual tentou ação de prescrição o considerou liberto. O Rvm. jamais pode ser livre na expressão da lei, na sua letra clara. Porquanto ficou provado (...) ter nascido de ventre escravo: e a lei diz claramente que só pode gozar de liberdade, se alcançar alforria. (...) O Rvm. o mais que pode subir na escala social é a camada dos LIBERTOS (O CATECHISTA, 12 de dezembro de 1863).

A impossibilidade de subir na escala social, imposta ao padre Daniel está presente no texto acima, matéria do Jornal $O$ Catechista, expõe a partir da fala do artigo a própria visão que se tinha a respeito dos grupos ligados aos escravos e ex-escravos, a condição intermediária destes, por sua origem. O escravo jamais seria um cidadão, seria no máximo liberto, por isso mesmo com restrições a sua cidadania.

Há na história do padre Daniel uma série de aspectos importantes que revelam de que maneira a questão racial é manejada nos debates jornalísticos e a forma como a cor do sacerdote (Padre Daniel era de acordo com os jornais, pardo e liberto, muitas vezes descrito como preto e escravo) depunha contra seus discursos e dimensionava negativamente suas ações. Para seus "inimigos políticos" o padre seria para sempre um ex-escravo.

Em agosto de 1860 o jornal Estrella do Amazonas publicou nota assinada pelo então escrivão Manoel do Nascimento Figueira, acusando Padre Daniel de querer ampliar sua atuação para além dos assuntos eclesiásticos. A nota do jornal é bem enfática ao retratar tanto a visão negativa a respeito da origem étnica do padre (ataca sua índole e faz alusão à cor da sua pele) quando o ameaça diretamente a cadeia e açoite:

O padre mestre não se contenta com o campo de sua parochia para fumentar a desordem, quer campo maior e achou que eu devia servir-lhe de pasto a sua loquacidade. Enganou-se completamente por que estou disposto a não despor mais de minha dignidade para dar troço a semilhante besta, a menos que não tire a mascara e appareça a peito descoberto, por que quero metel-o ainda uma vez na cadêa; ouvio padre mestre? Si esta lição, padre mestre, não vos serve ainda, então convencerás ao publico sensato, que só vergalho é que vos pode indireitar; mas qual! Preto quando não suja, tisna. (ESTRELLA DO AMAZONAS, 25 de agosto de 1860).

A ameaça fica evidenciada: só vergalho pode endireitar o padre. Logo depois preconceito toma conta das páginas do jornal: "preto quando não suja, tisna!” Aqui a presença das ofensas e ameaças evidenciam que a luta virulenta e de oposição às ações políticas do sacerdote ultrapassam os posicionamentos políticos e caem no campo do preconceito de raça particularmente presente no século XIX: a inferioridade dos negros, e sua impossibilidade de alcançarem a civilização pelas experiências do cativeiro. 
No mesmo mês e ano o jornal Estrella do Amazonas volta a ameaçar o Padre Daniel e desfere contra sua figura uma série de acusações sérias. Afirma ser o Padre o "evangelista do deboche e da prostituição".

Alude ao fato ao Padre lecionar para jovens acusando-o de aliciar suas alunas. Tal acusação não impediu o clérigo de solicitar junto às autoridades (e conseguir) a abertura de uma escola em Silves em novembro do mesmo ano. O jornal Estrella do Amazonas em uma de suas seções denominada parte oficial publicou nota da solicitação do Padre para abertura de uma escola em Novembro de 1863:

De Daniel Pedro Marques de Oliveira [VigarioCollado da Vila de Silves], pedindo permissão para abrir uma escola na freguezia de Silves, de grammatica latina, Franceza, retorica, e Philosophia racional. - Concedo a authorização requerida. Passe-se o competente título (ESTRELLA DO AMAZONAS, 28 de novembro de 1860).

Outra acusação feita no artigo do jornal é a de que padre Daniel teria, além de aliciar mulheres casadas e jovens inocentes (se aproveitando de sua condição de padre e professor) falsificou a carta de alforria de sua mãe para poder conseguir sua ordenação:

O padre mestre de Silves é o evangelista do deboche e da prostituição, solicita intra e extra confissões as mulheres casadas, solteiras e donzelas, e como prova cita-se d. Inácia, as menores que por suas artimanhas estiveram depositadas em sua casa aos seus desejos, e as meninas que (coitadinhas!) iam a sua casa a título de aprenderem a ler, beber o veneno da imoralidade (...) mandou chibatar e por em ferros um cidadão mais livre do que ele; conseguiu por suas astucias do tabelião João Corrêa registrar no seu cartório uma carta de liberdade, da preta f. sua mãe por ocasião de ser preterido em sua ordenação em consequência de exdefectuliberdatis (...) (ESTRELLA DO AMAZONAS, 22 de agosto de 1860).

A série de notas do jornal Estrella do Amazonas faz menção ainda a furto e imagens e relíquias da Igreja (atribuídas ao padre) e processos contra o mesmo ${ }^{3}$ :

(...) furtou $200 \$$ rs. dos cofres dos pontificaes, quando encarregado dessa repartição na sé do Pará; furtou segundo a participação do juiz de paz as joias das Imagens das igrejas de Silves e Jatapú finalmente, tem sido submettido a 3 ou 4 processos e prezo pelas suas altas virtudes. Tudo isto é meramente hypothetico, mas que o respeitável publico, caprixoso como é, pode converter, querendo, em verdades mathematicas (ESTRELLA DO AMAZONAS, 22 de agosto de 1860).

\footnotetext{
${ }^{3}$ O Jornal Estrella do Amazonas de 24 de março de 1860 solicita o envio da copia do processo que absolvia o Padre Daniel de uma destas acusações: "Ao juiz de direito interino da commarca da capital, determinando-lhe que envie com a possivel brevidade copiaauthentica da sentença proferida contra o vigario da villa de Silves Daniel Pedro Marques de Oliveira, no processo que foi submettido ao jury na $2^{a}$ sessão do anno passado, bem como a da absolvição em consequencia da decisão do jury”. O mesmo jornal em agosto ignora absolvição do sacerdote em uma das acusações.
} 
Notemos a partir da citação acima que o próprio texto do jornal afirma que todas estas acusações são meramente hipotéticas, mas mesmo assim presume-se pela "verdade matemática”.

Na crônica A Quinzena o padre é retratado como pescador de águas turvas que tem o interesse de transtornar a sociedade:

\begin{abstract}
A Quinzena
Manáos 24 de agosto de 1860

Todo corre placidamente; apenas um ou outro pescador d'aguas turvas trabalha com afan por transtornar este estado lisongeiro

Mas temos fé nos brios dos amasonenses que serão em tempo repellidos, como merecem, e conhecerão que o cabucolo do Amazonas tem nas suas flexas e fructos silvestres todos os elementos para resistirem a imposições de intruzos, que não teem o menor direito de intervir na direção de sua sorte (...). (ESTRELLA DO AMAZONAS, 24 de agosto de 1860.)
\end{abstract}

Evidencia-se a partir do termo pescador (em alusão a função sacerdotal?) de águas turvas que o objetivo e mais uma vez questionar a intervenção do Padre em assuntos diversos na comunidade de Silves. Turvas seria alusão a seu caráter? a sua cor da pele? Ou ambos? Importante frisar que o texto encerra-se afirmando que o padre não tem direito de interferir na sorte do "caboclo do Amazonas".

Notemos a presença da visão do caboclo a sua condição e herança da cultura indígena vista como oposta a civilização: a cultura material (portar flechas e comer frutos silvestres) aludidas no texto servem de exemplo também de como apresenta-se o preconceito também contra os indígenas e sua influência na sociedade.

As imposições de um intruso referem-se ao fato do Padre Daniel ser de fora da Província, nascido como vimos em Belém no final da década de 1820. O artigo acima citado demonstra preocupação em relação a atuação política do Padre, que se utiliza, segundo esta visão, de sua posição para intervir na vida da sociedade amazonense. O sacerdote é caracterizado negativamente e a forma como é definido sempre aludem ao fato de ser liberto, escravo, e ou preto, de acordo com o teor dos textos.

No jornal Estrella do Amazonas de 20 de junho de 1860 aparece tanto a preocupação quanto ao peso político do Padre Daniel, comparada a um "dedo de gigante", quanto a sua origem racial: cara branca e língua preta. No texto evidencia-se a ideia de que o padre utilizase de ardis para mascarar sua condição de liberto e procurar utilizando-se de sua posição como padre, gozar os privilégios de cidadão livre: 
Fazemos este pedido não por que não conheçamos pelo dedo o gigante, que (...) tem até hoje, por uma tolerância imperdoável, gozado dos foros de cidadão livre; mas por que queremos ter o prazer de ver a cara branca do Silviense - e língua preta (ESTRELLA DO AMAZONAS, 20 de junho de 1860.).

No mesmo jornal a ideia de que o padre esconde sua origem e atua de maneira criminosa fica evidente e mais uma vez se alude à condição do padre sempre presente de maneira dúbia: escravo ou liberto? Porém nunca como cidadão livre:

Rogo-lhe que tire a máscara, saia dos bastidores e acuse-me a peito descoberto sob pena de ser tido por criminoso escravo ou liberto, que teme a ação da justiça, a que chama perseguição - escravidão - e prepotência o que não podendo defender os seus parceiros escravos, que naquela vila gozavam dos foros de cidadãos (ESTRELLA DO AMAZONAS, 20 de junho de 1860).

A acusação que paira neste trecho é a de que o padre Daniel configura-se como acoitador de escravos. No texto os escravos são seus "parceiros". Alude-se ao fato de que o padre tenta atuar politicamente contra a escravidão para defender os escravos, utilizando-se ate do subterfugio de acoitar os mesmos. Compara-se o padre com os escravos fugitivos: estes gozavam de foros de cidadãos, pois escondiam sua origem e condição.

Em diversas passagens dos jornais os artigos relembram a condição de preta e escrava da mãe do padre Daniel, mesmo que nos documentos oficiais ela seja descrita como mulata. Aqui não importa a cor da pele e sim a vinculação da raça biologicamente falando. A própria condição do padre é assinalada de maneira dúbia, ora liberto, ora escravo, pardo, preto. A concepção de raça construída a partir da concepção biológica faz parte do ideário do século XIX.

\section{Conclusão}

Sobre o padre Daniel há muito mais para dizer. De início, é preciso salientar o fato de que se trata do primeiro negro de origem escrava a ocupar o cargo de deputado provincial e, tempos depois, de vice-presidente da Assembleia do Amazonas, nas legislaturas de 187677. Desconhecemos caso semelhante em todo o Império Brasileiro.

Mais do que isso, o que contamos aqui de sua história é suficiente para lembrar algo importante: revela-se a densidade histórica de um passado recente vivido pela sociedade amazonense pautado pela discriminação em bases raciais. Apesar da grande influência em Silves, aliado às principais autoridades daquela localidade (acusadas de acolher escravos 
fugidos), Daniel sofreu forte oposição das elites políticas de Manaus quando tentava abranger sua esfera de atuação política. No cerne das acusações e desqualificações que sofreu estava a cor de sua pele e o fato de ter sido escravo, ainda que libertado na pia batismal.

Apesar do que afirmava o Novo Testamento, dizia o editor do jornal Catechista, "no Brasil o fato é que nem todos são livres". Vale acrescentar: muitos, inclusive, viviam um cativeiro ilegal. Também não ajudou o argumento de que fora libertado no ato do batismo. Ainda restava o preconceito de cor. Como sugeria uma das crônicas jornalísticas citadas, ser negro no Amazonas significava possuir uma mancha inextirpável. Implicava, por outro lado, a definição de uma identidade estrangeira para os de origem africana, os tais "intrusos" discursos de interesse que buscavam marginalizar (e silenciar) negros e negras da vida pública e do seio das questões políticas, sociais e outros mais "assuntos amazonenses".

\section{Referências Bibliográficas}

\section{Fontes Impressas}

Jornais: Centro de Documentação e Apoio à Pesquisa - CENDAP/Acervo de Microfilmes - Estrella do Amazonas (1859-1860); O Catechista (1863)

\section{Falas e Relatórios}

Arquivo Público do Estado do Amazonas - Livro de Ofícios remetidos pela Câmara Municipal de Vila Bela 1873

Disponível em:

\section{http://brazil.crl.edu}

http://memoria.bn.br/hdb/periodo.aspx

\section{Anais da Assembleia Legislativa}

Anais da Assembleia Legislativa do Amazonas de 1870-1871. Manáos: Impresso na Typographia Industrial, p. 02-04, 1882.

Anais da Assembleia Legislativa do Amazonas do biênio 1872-1873. Manáos: Impresso na Typographia, do Amazonas, p. 02-04, 1882.

Disponível em:

http://www.aleam.gov.br/Legislacao_1871_1889/

\section{Obras consultadas}


BEZERRA NETO, José Maia. Fugindo, sempre fugindo: escravidão, fugas escravas e fugitivos no Grão-Pará (1840-1888). Campinas, SP: [s.n.], 2000.

CHALHOUB, Sidney. Trabalho, lar e botequim: o cotidiano dos trabalhadores no Rio de Janeiro da Belle Époque. São Paulo: Brasiliense, 1986.

CRUZ, Heloísa Faria de. Na Oficina do Historiador: Conversas sobre História e Imprensa.Projeto História, São Paulo, n. 35, p. 235-270, de. 2007.

FENELON, Déa Ribeiro. Cultura e História Social: Historiografia e pesquisa. Projeto História. São Paulo. 10. Dezembro de 1993.

GOMES, Ângela Castro Gomes. Cultura política: História e historiografia. In: Culturas políticas: ensaios de história cultural, história política e ensino de história. Rio de Janeiro: Mauad, 2005

JULLIARD, Jacques. A política. In: Fazer História, vol. 1. (Jacques Le Goff e Piere Nora). Livraria Bertrand, 1981, pp. 263-4.

NETO, Provino Pozza. Alforrias escravas na Província do Amazonas. In: O fim do silencio: presença negra na Amazônia. Belém: Editora açaí, 2011.

PINHEIRO, Maria Luiza Ugarte. Folhas do Norte. Letramento e periodismo no Amazonas (1880-1920). 2001. 287f. Tese (Doutorado). PUCSP, São Paulo 2001. 287p.

RÉMOND, René (org.). Por uma história do político. Estudos Históricos, Rio de Janeiro, vol. $5 \mathrm{n}^{\circ} 13,1996$.

Por que a história política. Rio de Janeiro: Editora UFRJ/Editora Fundação Getúlio Vargas, 1996.

SANTOS, F. J. et alli (orgs.). Cem anos de Imprensa no Amazonas: catalogo de jornais (1851-1950). $2^{\text {a }}$ ed. Revisada. Manaus: Ed. Umberto Calderaro, 1990.

SCHWARCZ, Lilia M. Retrato em Branco e Negro: jornais, escravos e cidadãos em São Paulo no final do século XIX. São Paulo: Companhia das Letras, 2008.

WILLIAMS, Raymond. Cultura. Rio de Janeiro: Paz e Terra, 1992.

ARTIGO ENVIADO EM: 16/01/2016

ARTIGO ACEITO PARA PUBLICAÇÃO EM: 31/12/2016 